\title{
CHARACTERIZATION OF ERD15 GENE FROM CULTIVATED TOMATO (Solanum lycopersicum)
}

\author{
Khurram Ziaf ${ }^{1,3}$, Muhammad Farooq Hussain Munis²,Ghufrana Samin ${ }^{4}$, Xiaohui Zhang ${ }^{3}$, Jinhua \\ $\mathbf{L i}^{3}$, Junhong Zhang ${ }^{3}$ and Zhibiao $\mathrm{Ye}^{3, *}$
}

\author{
${ }^{1}$ Institute of Horticultural Sciences, University of Agriculture, Faisalabad-38040, Pakistan; ${ }^{2}$ Department of Plant \\ Sciences, Faculty of Biological Sciences, Quaid-e-Azam University, Islamabad, Pakistan; ${ }^{3}$ National Key Laboratory of \\ Crop Genetic Improvement, Huazhong Agricultural University, Wuhan-430070, P.R. China; ${ }^{4}$ University of \\ Engineering and Technology (Lahore), Faisalabad Campus, Faisalabad, Pakistan. \\ "Corresponding author's e-mail: zbye@ mail.hzau.edu.cn
}

\begin{abstract}
Expression profile of a gene in response to various abiotic and biotic stresses provides an insight in to its possible role in stresses. An Early Responsive to Dehydration (ERD) 15 gene (SIERD15) was cloned from the cultivated tomato (Ailsa Craig) having open reading frame of $486 \mathrm{bp}$ and an intron of $102 \mathrm{bp}$. SlERD 15 encodes 162 amino acids in contrast to 156 amino acids of previously reported ERD15 (SGN-U214024). SIERD15 encoded protein has a conserved motif PAM2. SIERD15 transcript accumulation was higher in older leaves and tomato fruit at colour break stage than in other plant organs. Expression profile revealed increase in transcript level of SIERD15 on exposure of Ailsa Craig to dehydration (drought), salinity, ABA, ethylene, $\mathrm{GA}_{3}$ and salicylic acid. Messenger RNA level of SIERD15 was decreased initially followed by increase in response to heat and wounding stress. While, transient rise in mRNA level of SlERD15 was noticed in response to cold stress. The transcript accumulation during seed imbibition also revealed its involvement in early responses due to osmotic stress. There was a clear difference in mRNA level of ERD15 from two (Solanum lycopersicum and S. pennellii) species when observed round the clock. This difference in expression patterns as well as in amino acid sequence provides a clue of diversity in function and regulatory mechanism of the gene from two different sources. Moreover, some information about some other putative $E R D$ genes from tomato has been presented.
\end{abstract}

Keywords: Genes expression, Ailsa Craig, drought, ABA, $\mathrm{GA}_{3}$, Circadian Rhythm.

\section{INTRODUCTION}

Plant physiology, morphology and biochemistry are genetically controlled by a large set of genes. Expression of these genes is influenced by a number of factors, internal as well as external, including stage of plant development, diseases, drought, salinity, cold, and many others (Yoshioka et al., 2003; Zhang et al., 2001). Some genes are activated or suppressed by a specific stress factor while, many genes respond to more than one stimulus (Kariola et al., 2006). These genes can be classified, on the basis of their expression patterns and/or their responsiveness to environmental stressors, in different groups viz., responsive to dehydration (RD), cold regulated (COR), cold inducible (KIN), lowtemperature induced (LTI), early responsive to dehydration (ERD), salt overly sensitive (SOS), dehydration-responsive element-binding proteins (DREBs) and many more (Shinozaki and Yamaguchi-Shinozaki, 2007; Mahajan and Tuteja, 2005).

Among these genes, ERDs have emerged as a new class or group of genes, identified first time by Kiyosue et al. (1994) in Arabidopsis plants dehydrated for one hour. Some members of the ERD group have been studied such as ERD1 (that encodes a Clp protease regulatory subunit; Nakashima et al., 1997), ERD5 (proline dehydrogenase; Kiyosue et al., 1996), ERD8 (hsp8-1; Takahashi et al., 1992), ERD10 (Group II LEA protein = lti29/lti45; Welin et al., 1995) and ERD15 (Kariola et al., 2006; Alves et al., 2011; Ziaf et al., 2011). Among these ERD genes, ERD15 has been used as a stress responsive gene in various stress experiments (Dunaeva and Adamska, 2001; Park et al., 2009; Li et al., 2010) in Arabidopsis and wheat. Nevertheless, its induction and function has been contradictory (Kariola et al., 2006; Ziaf et al., 2011), which can be due to difference in sequence among the species and/or due to some mutations in the sequence from specific crop.

Transcript of several genes is accumulated at a specific stage of plant growth or in specific organs, varying to some extent with their function. Some are under the control of endogenous circadian system and thus affect the physiology and metabolism (Yakir et al., 2007). About 6\% genes in Arabidopsis, involved in various functions such as photosynthesis, responses to stresses, sugar metabolism and flowering in response to day-length, fluctuate daily and are controlled by circadian clock (Harmer et al., 2000). Wang and Grumet (2004) reported diurnal pattern for transcript level of 
AtERD15, increasing during the day and decreasing at night. But, no information is available on ERD15 transcript regulation round the clock in tomato.

Therefore, transcript profile of ERD15 in response to various stress factors and growth regulators, in different organs as well as during seed germination in the cultivated tomato cv. Ailsa Craig was studied. Circadian rhythm of SIERD15 was compared with that of SpERD15. Moreover, in silico approach was also employed to predict protein localization and presence of motif in SIERD15 as well as its homologues. Results revealed increase in transcript level of SIERD15 in response to plant growth regulators and abiotic stresses except heat and wounding stresses. Circadian rhythm of SlERD15 was quite different from SpERD15. Possible reason of difference in expression level two species has been discussed.

\section{MATERIALS AND METHODS}

Gene cloning and Bioinformatics analysis tomato (Solanum lycopersicum) cultivar Ailsa Craig was used to amplify the ERD15 gene (later on termed as SIERD15) from both cDNA and genomic DNA (gDNA) using the primers (Table 1). DNA was extracted using CTAB method. Total RNA from tomato plants was isolated using the TRIzol reagent (Invitrogen, USA) according to the manufacturer's instruction and was treated with DNaseI. The quality of RNA was checked on a denaturing formaldehyde gel and further confirmed by measuring the ratio of A260/A280. Total RNA was then reverse transcribed using MMLV (TOYOBO) reverse transcriptase and Oligo (dT). The resulting cDNAs were used for the amplification of the target gene (from unstressed plants) and expression analysis (stress treatments) using gene specific primers. Primer pair SIERD15 was used to amplify gene using DNA and cDNA, while SIERD15 qRT-PCR primer pair was used for quantitative real-time (qRT) PCR. The amplified product was cloned into pMD18-T vector, and the cloning vector was then introduced into E. coli strain DH5 $\alpha$. The positive clones of E. coli were selected through PCR and sequenced (Invitrogen) for further use.

\begin{tabular}{ll}
\hline Primer & Sequence $\left(\mathbf{5}^{\prime}\right.$ to $\mathbf{3}^{\prime}$ ) \\
\hline SIERD15 Fw & ATTTGGAGAAAGAGAATGGCGTTA \\
SIERD15 Rv & AGAACCAAACATCAAACCCACATAC \\
SIERD15 Fw qRT-PCR & AGGCATCAAGTCATCACTCTCTGGT \\
SIERD15 Rv qRT-PCR & GAGGTAAATGTGAGTAAGAACCAACG \\
BActin Fw qRT-PCR & GTCCTCTTCCAGCCATCCAT \\
BActin Rv qRT-PCR & ACCACTGAGCACAATGTTACCG \\
\hline
\end{tabular}

Bioinformatics analyses: The sequencing results were used to get predicted peptide for SIERD15 using Genescan (MIT, Cambridge, MA) and Softberry. Intron in the genomic DNA was computed by the Splign tool at NCBI (http://www.ncbi.nlm.nih.gov/sutils/splign/splign.cgi). The molecular weight, pI, and total number of positively and negatively charged residues were predicted using the ExPASy
ProtParam tool (http://us.expasy.org/tools/ protparam.html). Subcellular localization was predicted using CELLO v.2.5 (http://cello.life.nctu.edu.tw) and further confirmed with ProComp v 8.0 (http://linux1.softberry. com/berry). The presence of nuclear export signal was estimated from NetNES 1.1 server (http://www.cbs.dtu.dk/ cgi-bin). To find similar sequences in the tomato genome, blast result from SOL genomics network (http://www. solgenomics.net) was used. To identify similarity among the sequences acquired from blast results, alignment was performed using the ClustalW2 (http://www.ebi.ac.uk/Tools/msa/clustalw2/).

Stress treatments and transcript analysis: Expression of SIERD15 was detected in different organs of Ailsa Craig plants, during germination of $\mathrm{AC}$ seeds, as well as in response to different stresses. Five plants were used for each stress assay and were placed in greenhouse according to completely randomized design. Dehydration stress was imposed by detaching leaves from plants and kept on clean bench under cool white fluorescent light. One-month-old transgenic plants were also sprayed with $\mathrm{NaCl}(200 \mathrm{mM}), \mathrm{ABA}(100 \mu \mathrm{M})$ and GA $(100 \mu \mathrm{M})$, SA $(0.5 \mathrm{mM})$ or ethephon $(1 \mathrm{mM})$. For cold $\left(4^{\circ} \mathrm{C}\right)$ and heat $\left(40^{\circ} \mathrm{C}\right)$ stress, one month old plants were exposed to the specified temperature for four hours. Leaves were scratched with blade for wounding. Leaf samples were collected at $0,1,3,6$ and $12 \mathrm{~h}$ after each treatment. While, for assessment of circadian rhythm, samples were collected round the clock. To monitor SIERD15 mRNA changes during seed germination, samples of imbibed seeds were drawn 12, 24, 48 and 72 hours after start of germination test. Expression pattern of SIERD15 was analyzed using semi-quantitative RT-PCR (for organ specific expression) and qRT-PCR (for expression analysis of stress, seed germination and circadian experiments) essentially as described previously (Ziaf et al., 2011). Briefly, PCR to amplify SIERD15 and semiquantitative RT-PCR were programmed as: initial denaturation at $95^{\circ} \mathrm{C}$ for $10 \mathrm{~min}$, followed by 25 cycles $(30$ cycles for SIERD15 amplification) of $95^{\circ} \mathrm{C}$ for $1 \mathrm{~min}, 58^{\circ} \mathrm{C}$ for $30 \mathrm{~s}$ and $72^{\circ} \mathrm{C}$ for $1 \mathrm{~min}(2 \mathrm{~min}$ for amplification of SIERD15 using DNA as template), and finally $72^{\circ} \mathrm{C}$ for 10 minutes. Real-time RT-PCR was performed in triplicate in an optical 96-well plate using a LightCycler 480 (Roche) PCR system. The qRT-PCR cycling program was as follows: initial denaturation at $95^{\circ} \mathrm{C}$ for $10 \mathrm{~min}$, followed by 40 cycles of $95^{\circ} \mathrm{C}$ for $10 \mathrm{~s}, 60^{\circ} \mathrm{C}$ for $20 \mathrm{~s}$ and $72^{\circ} \mathrm{C}$ for $20 \mathrm{~s}$. The expression data were analysed by the $\Delta \Delta \mathrm{Ct}$ method using the threshold cycle (Ct value), generated by the LightCycler 480 (Roche) PCR system (Schmittgen and Livak, 2008).

\section{RESULTS}

Characterization of SIERD15: The SIERD15 gene was amplified from the cultivated tomato cultivar Ailsa Craig. The full-length open reading frame of SIERD15 contained $486 \mathrm{bp}$, while the genomic DNA has an intron of 102 bp (Fig. 1). 
SIERD15 also encodes 162 amino acids, similar to SpERD15, however, in contrast to 156 for previously reported ERD15 for the cultivated tomato (SGN-U214024 available at SOL genomics network).

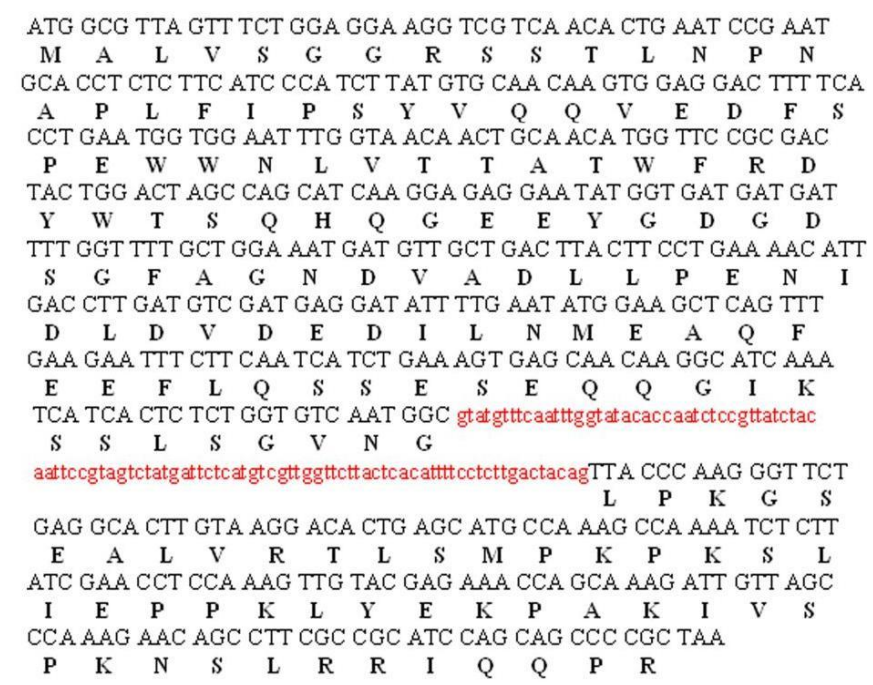

Figure 1. Nucleotide and deduced amino acid sequences of SIERD15. Capital letters correspond to coding region and amino acids (bold). Intron is represented by letters in lower case.

The predicted protein had molecular weight of $18.19 \mathrm{kDa}$ and pI value of 4.47 . Its protein has 25 negatively and 14 positively charged residues. The computed instability index of the predicted peptide was 56.40 that classified it as unstable protein. Moreover, the predicted peptide was supposed to be localized in the nucleus, and can be exported to cytoplasm as revealed by prediction results. So, we further confirmed the presence of nuclear export signal, which were found in predicted peptide (amino acid \# 70 to 84: "LDVDED"), which might need further confirmation. Search for sequences, having similarity with SIERD15, revealed two unigenes viz., SGN-U584750 and SGN-U584748 that had 83\% and 99\% similarity, respectively (Data not shown). Besides these two unigenes, three other sequences (SGN-U581174, SGNU578781 and SGN-U604373) showed 61\% to 68\% similarity with SIERD15 on nucleotide basis. However, on peptide basis, all the proteins had more than $70 \%$ similarity with SIERD15 except SGN-U604373, for which it was just $40 \%$. Furthermore, query for motif in the predicted proteins of these genes revealed the presence of PAM2 motif in all unigenes except SGN-U604373 (Fig. 2).

Expression profile of SIERD15: Tissue specific analysis revealed abundance of SIERD15 mRNA in root, old leaves and fruit at breaker stage, and comparatively lower in flower and ripened fruit (Fig. 3).
SXTL.FFHAPLFX
SIERD15

SGN-U584750

SGN-U584748

SGN-U578781

SGN-U581174

SGN-U604373

SIERD15

SGN-U584750

SGN-U584748

SGN-U578781

SGN-U581174

SGN-U604373

SIERD15

SGN-U584750

SGN-U584748

SGN-U578781

SGN-U581174

SGN-U604373

SIERD15

SGN-U584750

SGN-U584748

SGN-U578781

SGN-U581174

SGN-U604373

SIERD15

SGN-U584750

SGN-U584748

SGN-U578781

SGN-U581174

SGN-U604373

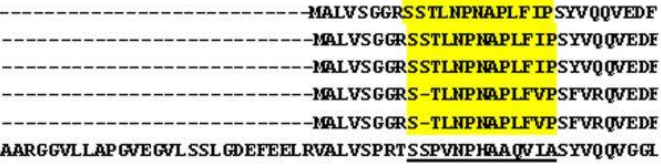

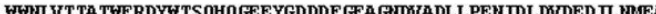
FRLVTTA THFRDYHTSQHQGEEYGDDDF GFAGRDVADLLPENIDLDVDEDILMIFA WHRLVTTATHFRDYTT SQHQGEEYGDDF GFAGIDVADLLPENIDLDVDEDILRIEA FFHLVTTS TWFYDYHASQHQGEEYG------AGKDVADLLPENIDLKVDEDILNAFA

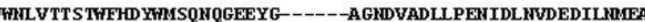
HGGSHRTAEWFPDYRTPCTWGKEIGDDDFDFAGIDVARLLPEQIGRAVHKDIFRAEG

EFLQSSESEQQGIKSSLSGUN-

EFLQSSESEQQGIKSSLSGVITGIF QFGT-

EFL OSSESE00GIKSSLSGUN-

EFLQSSEHEQQGIKSSLYGVIAIPQY WEOGIKSSLYGWIAMPQYGMARLSISCL TYSQQKDHVRFAWF TEVLVQ HFLAASYRLVAHTHOVSGYY--

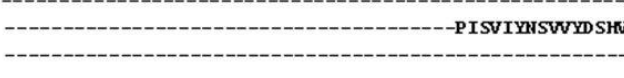

TEKSEEPLAIRSL YYKLUESGDPAGVGICVSLLKODGKIPTCLVLVVIIFGVY

-----GLPKGSEALVRTLSTIPKPKSLIEPPKLYEKPAKTVSPKKSLRRIQQPR FLLT TGL PKGSEALVRTL SIIPKPKSL IEPPKL YEKPAKIVSPKWSL RRT OOPR -----GLPKGSEALVRTL SIPKPKSL IEPPKL YEKPAKIVSPKNSLRRIQQPR -------GLPSDALIRTLSSPR--SPIGPPKYFEKPSKIVSPRWSFRSIQQPR LLKLDKTGLPSDALIRTLSSPR--SPIGPPKYFEKPSKIVSPRNSFRSIQQPR

Figure 2. Comparison of predicted amino acid sequences of genes showing similarity with SIERD15, available in SOL genomics database. PAM2 Motif was underlined and highlighted.

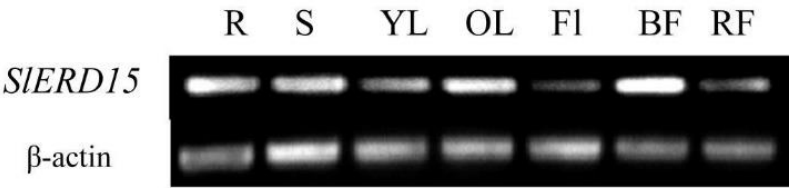

Figure 3. Expression profile of SIERD15 in different organs (R, root; S, stem; YL, young leaf; OL, old leaf; Fl, flower; BF, fruit at colour break stage; RF, ripe fruit) of Ailsa Craig obtained through semi-quantitative RT-PCR.

Transcript regulation of SIERD15 was studied under abiotic stress and biotic stress elicitors to dissect its induction in tomato. Real-time RT-PCR analysis showed transcript upregulation by all the stress treatments (Fig. 4, 5, 6). Steady state increase in SIERD15 transcript accumulation was observed in response to dehydration (drought) after one hour reaching maximum after six hours of treatment (Fig. 4). Salt stress increased mRNA level of SIERD15 after three hour of treatment and started to decrease after six hours, and was still higher than the control after 12 hours of treatment (Fig. 4). Both, heat and wounding stress suppressed SlERD15 transcript level for a short time and then increased (Fig. $4 \&$ 6 ). While, cold stress induced transient rise in mRNA level of SIERD15 for very short time. Increased transcript level of 
SIERD15 was recorded after one hour of treatment with ABA, GA3 and salicylic acid (SA) that continued to increase till 12 hours (Fig. 5 \& 6). Transcript level also increased in response to ethylene (ethephon), after 3 hours of treatment (Fig. 5).
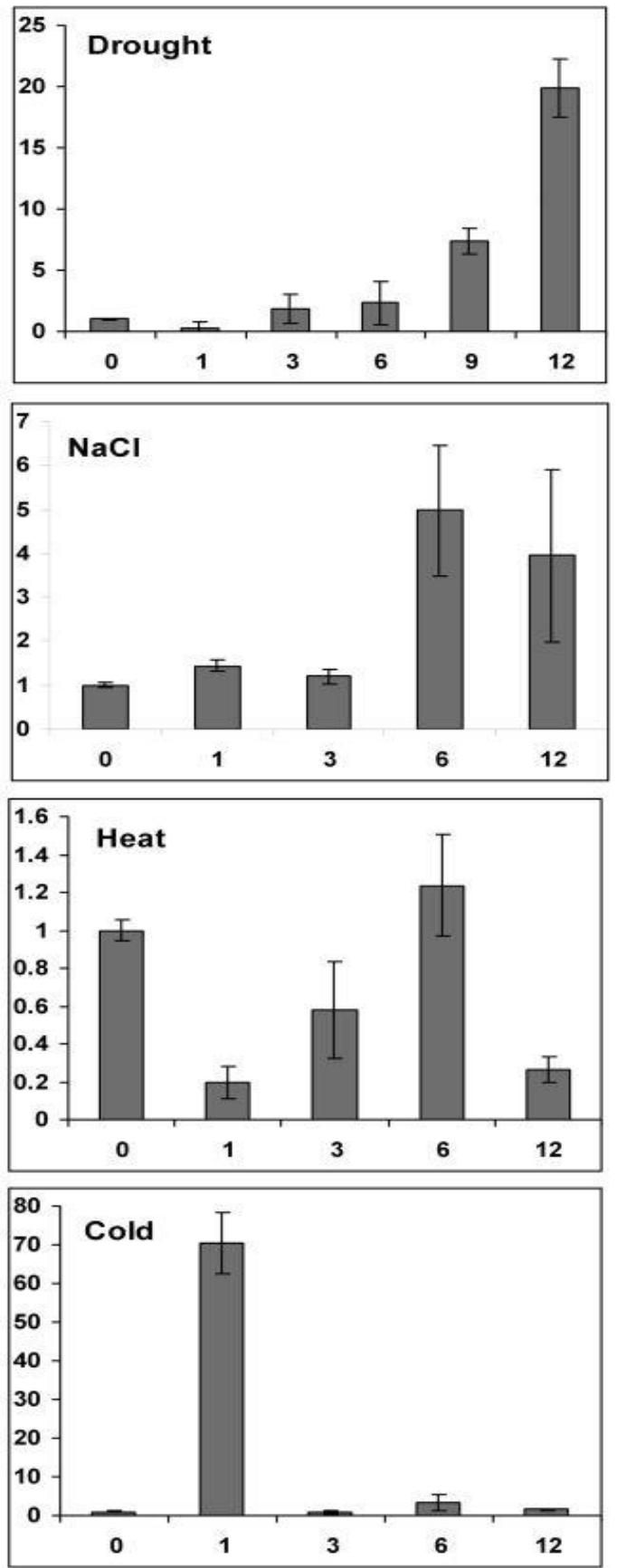

Time (hours)

Figure 4. Expression profile of SIERD15 in response to drought, $\mathrm{NaCl}$, cold and heat stress.
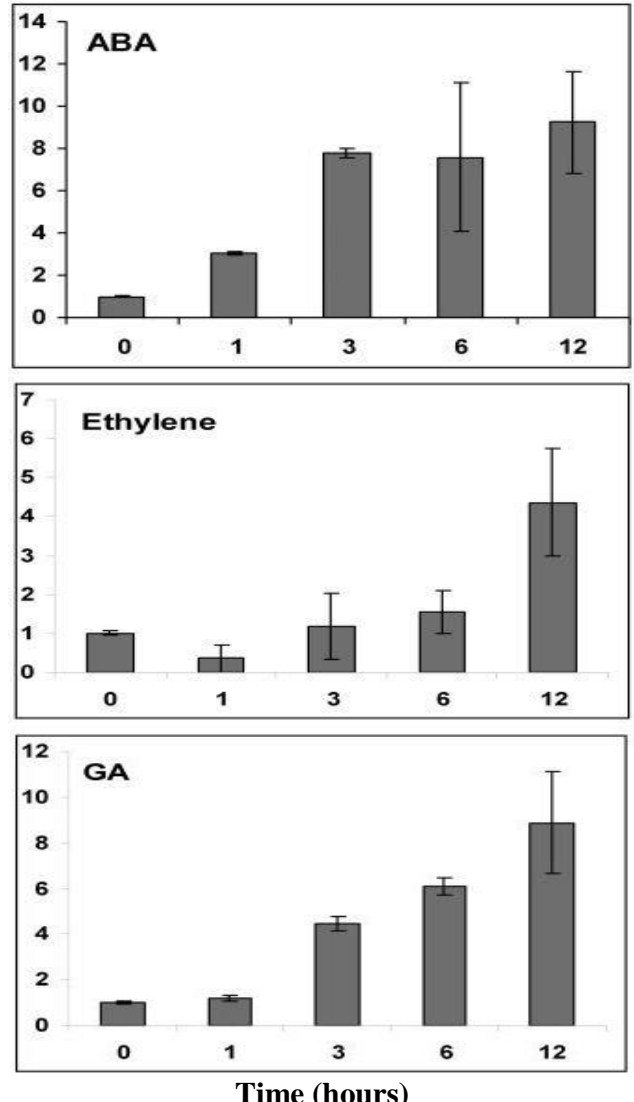

Figure 5. Transcript level of SIERD15 in Ailsa Craig plants treated with $\mathrm{ABA}(100 \mu \mathrm{M})$, Ethylene (1 mM ethephon) and GA $(100 \mu M)$.
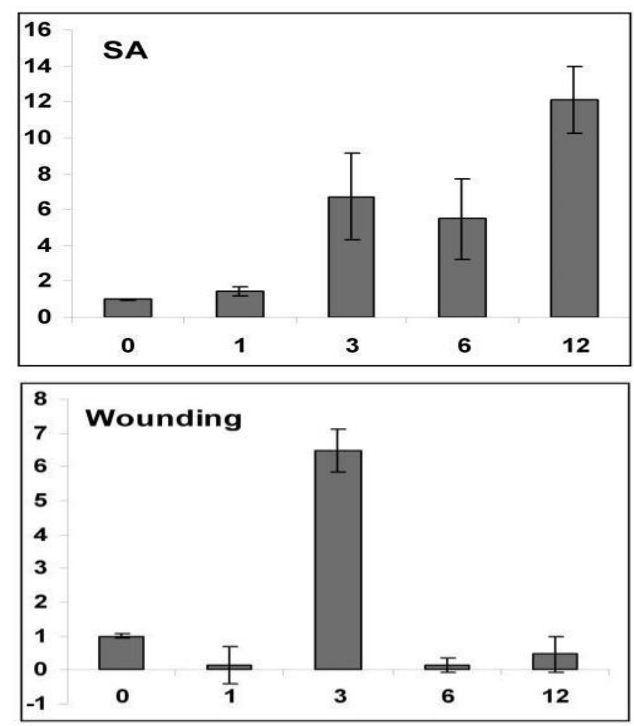

Time (hours)

Figure 6. Changes in SIERD15 mRNA level in Ailsa Craig plants after wounding or spray with SA (100 $\boldsymbol{\mu M})$. 
SIERD15 transcript accumulation seemed to oscillate diurnally, as expression started to decrease from morning (6 am) till afternoon (3 pm), after which mRNA level of SIERD15 was increased (Fig. 7b). This increase in transcript level continued till mid night $(12 \mathrm{pm})$ and then declined to normal level (as were in the morning). We also determined the change in transcript level of SpERD15 from 9.00 am to $5.00 \mathrm{pm}$ (because SIERD15 transcript showed variation during this period), continued progressive increase till evening $(5.00 \mathrm{pm})$ in contrast to SIERD15 (Fig. 7a).
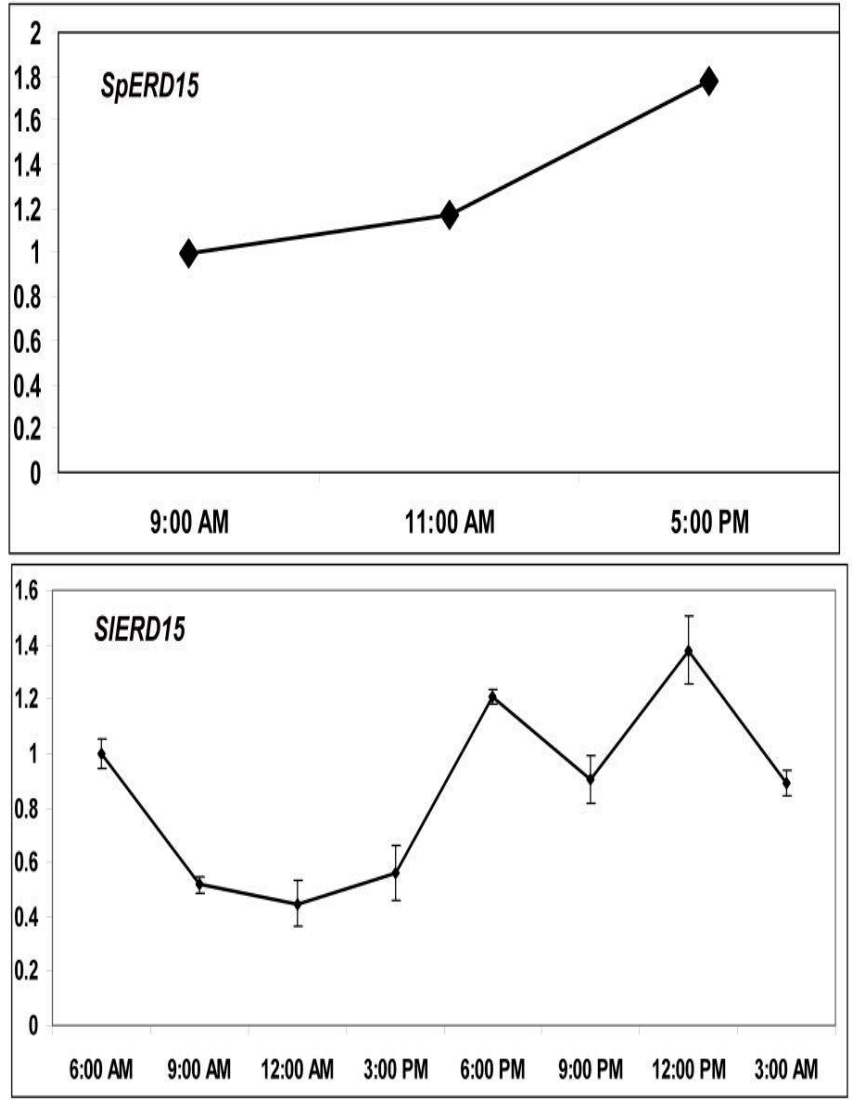

Time of sample collection

Figure 7.Circadian rhythm in transcript levels of SpERD15 and SIERD15.

Tomato seed, being a solanaceous crop, has embryo embedded in the endosperm at the time of seed maturity (Maki and Morohashi, 2006) and are non-starchy in nature. These both characteristics of tomato seed restrict the availability of appropriate volume water to embryo and may possibly contribute to some sort of osmotic stress to the embryo during germination. Therefore, expression pattern of the SIERD15 was observed during seed germination. Results revealed slight increase in SIERD15 transcript level after 24 hours, which remained high till 48 hours i.e. during imbibition and then declined to normal value after 72 hours (Fig. 8).

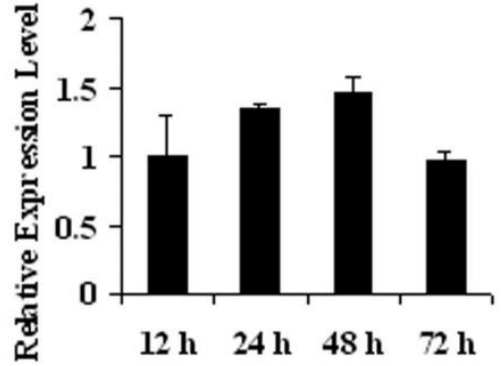

Time of sample collection

Figure 8. Change in expression level of SIERD15 during seed germination of tomato cv. Ailsa Craig.

\section{DISCUSSION}

Several stress-responsive genes have been reported to be regulated prior to $\mathrm{ABA}$-induced expression of $\mathrm{ABA}$ - as well as stress-responsive genes (Kiyosue et al., 1994). Kiyosue et al. (1994) isolated several genes, induced before the accumulation of ABA, from Arabidopsis plants dehydrated for $1 \mathrm{~h}$ and termed these genes as Early Responsive to Dehydration (ERD). Some members of this group have been analyzed for their functional significance (Welin et al., 1995; Kariola et al., 2006; Alves et al., 2011b). ERD15 has been characterized in different plant species but there has been dissension in its role (Kariola et al., 2006; Li et al., 2010; Ziaf et al., 2011) that can be attributed to differences in amino acid sequence. This suggests that the same gene from two different genotypes (varieties, strains and/or species) may have variation in their sequence as well as expression patterns. Therefore, we analyzed the nucleotide and peptide sequence as well as expression profile of SIERD15 in cv. Ailsa Craig in response to different abiotic stresses and growth regulators. SIERD15 shared structural features with previously reported SpERD15 by encoding same number of charged residues and total amino acids as well as an intron of almost same length (102 bp). Nevertheless, there was difference of some amino acids between SIERD15 and SpERD15 due to substitution (Ziaf et al., 2011). Search for similar sequences in the tomato database (SOL Genomics Netwroks) revealed four more unigenes that showed similarity (more than $70 \%$ ) with the predicted SIERD15 protein, indicating the existence of several members of ERD15 in tomato. A PAM2 motif, which is a conserved amino acid domain among human, mice, Drosophila, cucumber and Arabidopsis, and interact with Poly(A) Binding Protein was also present in SIERD15 (PABP; Wang and Grumet, 2004). PABPs function as cisacting effectors in polyadenylation to regulate the length and stimulation of mRNA maturation, mRNA export from nucleus, translation of mRNA, and turnover of the transcript to which they are associated for polyadenylation (Mangus $e t$ al., 2003). 
Expression profiling revealed differential accumulation of SlERD15 transcript in plant tissues. The SIERD15 mRNA level increased with age of the leaf as well as with the onset of ripening process in fruit indicating that it may be associated with the senescence process. Moreover, root and stem also had abundance of SIERD15 mRNA. It can be assumed on the basis of expression profile that SIERD15 is developmentally regulated just like its homologue from $S$. pennellii. In spite of some similarities between SIERD15 and SpERD15, the expression patterns in response to stresses and growth regulators were quite different. Transcript accumulation of SIERD15, in contrast to the rapid increase of SpERD15 expression (reaching maximum after $3 \mathrm{~h}$ of dehydration and then declined) (Ziaf et al., 2011), continued to increase gradually after $1 \mathrm{~h}$ of treatment till $6 \mathrm{~h}$, more or less similar to AtERD15 (Kariola et al., 2006). Cold stress increased SIERD15 mRNA levels transiently for a short time but had been reported to increase gradually in case of SpERD15 (Ziaf et al., 2011). Moreover, ERD15 transcription in S. lycopersicum was different from $\mathrm{S}$. pennellii when treated with ABA, ethylene and GA3. Furthermore, SA and wounding induced transcriptional changes of SIERD15 were similar to those reported by Kariola et al. (2006) for AtERD15. Circadian rhythm of SIERD15 showed decline in transcript up to $3 \mathrm{pm}$ followed by rise up to 12 am while, SpERD15 transcript showed continuous increase from 9 am to $6 \mathrm{pm}$. Wang and Grumet (2004) noticed decreased in mRNA level of AtERD15 from 4 am to 8 am followed by increase till $12 \mathrm{am}$. and then reduced again. This similitude in expression of SIERD15 and AtERD15 indicates the possibility of same mechanism of action of two genes while, different from that of SpERD15. Besides this difference in expression, a common feature of ERD15 from different species was the expression of these genes under stress as well as ABA treatments (Kariola et al., 2006; Ziaf et al., 2011).

Water uptake by a mature dry seed follows a triphasic pattern i.e., a rapid initial uptake (phase I) followed by a plateau phase (phase II) and finally the increase in water uptake resulting in radicle protrusion commencing the germination. Expression of SIERD15 increased till start of the plateau phase (48 hours) and then declined. It can hypothesized that wrapping of embryo by the endosperm might have limited water supply to the embryo (Maki and Morohashi, 2006) and thus created a partial osmotic stress in the beginning that triggered increase in transcription of SIERD15 and not by the endogenous GA3 levels (Ogawa et al., 2003; Perez-Flores et al., 2003).

Conclusion: SIERD15 transcript accumulated more in older leaves and fruit at colour change stage which reflects its association with senescence related processes. Although, amino acid substitutions were recorded between SlERD15 and SpERD15 yet, protein of gene from both species showed nuclear localization. Moreover, difference in expression patterns of SIERD15 and SpERD15 depicts differential function and mechanism of action.

Acknowledgment: This work was supported by the Ministry of Science and Technology of China [973 Project, grant No. 2009CB119000]; the National Science Foundation of China [grant Nos. 30871712 and 30921002). The first author extends his gratitude to the Ministry of Education, Pakistan, and the China Scholarship Council for providing the opportunity to pursue studies in China.

\section{REFERENCES}

Alves, M.S., P.A.B. Reis, S.P. Dadalto, J.A.Q.A. Faria, E.P.B. Fontes and L.G. Fietto. 2011. A novel transcription factor, ERD15 (Early Responsive to Dehydration 15), connects endoplasmic reticulum stress with an osmotic stress-induced cell death signal. J. Biol. Chem. 286:20020-20030.

Dunaeva, M. and I. Adamska. 2001. Identification of genes expressed in response to light stress in leaves of Arabidopsis thaliana using RNA differential display. Eur. J. Biochem. 268:5521-5529.

Harmer, S.L., J.B. Hogenesch, M. Straume, H.S. Chang, B. Han, T. Zhu, X. Wang, J.A. Kreps and S.A. Kay. 2000. Orchestrated transcription of key pathways in Arabidopsis by the circadian clock. Science 290:21102113.

Kariola, T., G. Brader, E. Helenius, J. Li, P. Heino and E.T. Palva. 2006. Early responsive to dehydration 15, a negative regulator of abscisic acid responses in Arabidopsis. Plant Physiol. 142:1559-1573.

Kiyosue, T., K. Yamaguchi-Shinozaki and K. Shinozaki. 1994. Cloning of cDNAs for genes that are earlyresponsive to dehydration stress (ERDs) in Arabidopsis thaliana L.: Identification of three ERDs as HSP cognate genes. Plant Mol. Biol. 25:791-798.

Kiyosue, T., Y. Yoshiba, K. Yamaguchi-Shinozaki and K. Shinozaki. 1996. A nuclear gene encoding mitochondrial proline dehydrogenase, an enzyme involved in proline metabolism, is upregulated by proline but downregulated by dehydration in Arabidopsis. Plant Cell 8:1323-1335.

Li, S., C. Xu, Y. Yang and G. Xia 2010. Functional analysis of TaDi19A, a salt-responsive gene in wheat. Plant Cell Environ. 33:117-129.

Mahajan, S. and N. Tuteja. 2005. Cold, salinity and drought stresses: An overview. Arch Biochem. Biophy. 444:139158.

Maki, H. and Y. Morohashi. 2006. Development of polyphenol oxidase activity in the micropylar endosperm of tomato seeds. J. Plant Physiol. 163:1-10.

Mangus, D.A., M.C. Evans and A. Jacobson. 2003. Poly(A)binding proteins: multifunctional scaffolds for the 
posttranscriptional control of gene expression. Genome Biol. 4:223.1-223.14.

Nakashima, K., T. Kiyosue, K. Yamaguchi-Shinozaki and K. Shinozaki. 1997. A nuclear gene encoding a chloroplast targeted Clp protease regulatory subunit homolog is not only induced by water stress but also developmentally upregulated during senescence in Arabidopsis thaliana. Plant J. 12:851-861.

Ogawa, M., A. Hanada, Y. Yamauchi, A. Kuwahara, Y. Kamiya and S. Yamaguchi. 2003. Gibberellin biosynthesis and response during Arabidopsis seed germination. Plant Cell. 15:1591-1604.

Park, M.Y., M.S. Chung, H.S. Koh, D.J. Lee, S.J. Ahn and C.S Kim. 2009. Isolation and functional characterization of the Arabidopsis salt-tolerance 32 (AtSAT32) gene associated with salt tolerance and ABA signaling. Physiol. Plant. 135:426-435.

Perez-Flores, L., F. Carrari, R. Osuna-Fernandez, M.V. Rodriguez, S. Enciso, R. Stanelloni, R.A. Sanchez, R. Bottini, N.D. Iusem and R.L. Benech-Arnold. 2003. Expression analysis of a GA 20-oxidase in embryos from two sorghum lines with contrasting dormancy: possible participation of this gene in the hormonal control of germination. J. Exp. Bot. 54:2071-2079.

Shinozaki, K. and K. Yamaguchi-Shinozaki. 2007. Gene networks involved in drought stress response and tolerance. J. Exp. Bot. 58:221-227.
Takahashi, T., S. Naito and Y. Komeda. 1992. Isolation and analysis of expression of two genes for the 81-kilodalton heat-shock proteins from Arabidopsis. Plant Physiol. 99:383-390.

Wang, X. and R. Grumet. 2004. Identification and characterization of proteins that interact with the carboxy terminus of poly(A)-binding protein and inhibit translation in vitro. Plant Mol. Biol. 54:85-98.

Welin, B.V., A. Olson and E.T. Palva. 1995. Structure and organization of two closely related low-temperatureinduced DHN/LEA/RAB-like genes in Arabidopsis thaliana L. Heynh. Plant Mol. Biol. 29:391-395.

Yakir, E., D. Hilman, Y. Harir and R.M. Green. 2007. Regulation of output from the plant circadian clock. FEBS J. 274:335-345.

Yoshioka, R., K. Soga, K. Wakabayashi, G. Takeba and T. Hoson. 2003. Hypergravity-induced changes in gene expression in Arabidopsis hypocotyls. Adv. Space Res. 31:2187-2193.

Zhang, X., L. Zhang, F. Dong, J. Gao, D.W. Galbraith and C.P. Song. 2001. Hydrogen peroxide is involved in abscisic acid-induced stomatal closure in Vicia faba. Plant Physiol. 126:1438-1448.

Ziaf, K., R. Loukehaich, P. Gong, H. Liu, Q. Han, T. Wang, H. Li and Z. Ye. 2011. A multiple stress responsive gene ERD15 from Solanum pennellii confers stress tolerance in tobacco. Plant Cell Physiol. 52:1055-1067. 